\title{
PUBLIC ENGAGEMENT WITH, AND TRUST IN, ONLINE NEWS MEDIA IN FRENCH-SPEAKING BELGIUM
}

\begin{abstract}
Omar Rosas ${ }^{1}$
This paper analyzes the French-speaking Belgian public's reception of, and trust in, online news media. Based on a qualitative research carried out in 2009-2010, it will be shown that respondents have different levels of engagement with online media, hold divided conceptions of media credibility and trust, and negotiate different levels of media-related assurance. Furthermore, respondents appeared to draw upon four heuristics to decide whether or not they trust online news: transparency, accountability, reputation, and recommendation. The relevance of these heuristics to trust is clear insofar as they affect both newsreaders' attributions of trustworthiness to, and engagement with, online journalists and news media. At the end of the paper, some conclusions about trust in online news are discussed.
\end{abstract}

\section{Public Engagement with and Trust in Online News Media in French-speaking Belgium}

Over the past decade, online news media have been constantly striving not only to consolidate their niches as primary informers within the ever-growing mediasphere, but also to earn audiences' trust by strengthening their credibility markers and by looking for reconnecting with the public's demands for participation and unbiased reporting. To carry out this task appropriately, online news media are drawing on the technological affordances provided by social computing

1 Omar Rosas is Postdoctoral Researcher at the Université de Namur.

Recherches en communication, $\mathrm{n}^{\circ} 40$ (2013). 
tools (e.g., social networks, blogs, etc.) in order to capitalize on new information and communication strategies for improving their day-today journalistic practices. However, the adoption of such technological affordances has a deep impact on how audiences come to appraise online journalism and whether or not they feel motivated to trust online journalists and news organizations. In this spirit, the aim of this paper is threefold: to examine how the French-speaking Belgian newsreaders engage with online media, how they conceive of trust in online news, and what criteria they draw upon to decide whether or not to trust online news media.

\section{Framing the Issue: Public Trust in Online News Media}

One of the distinctive features of our contemporary Information Society is the way in which the domestication of Information and Communication Technologies has reconfigured most of our private and public activities, including those related to information seeking, social relatedness, entertainment, health advice, financial transactions, and political participation among others (Silverstone \& Hirsh, 2005). Such a reconfiguration has also taken place within the domain of news production and consumption, so that traditional ways of doing journalism are undergoing deep transformations from within and merging with new technology-inspired modes of content creation and diffusion (Meikle \& Redden, 2011). Furthermore, users of new media technologies and the so-called Web 2.0 have been empowered so that they too can actively participate in a virtual space which is no longer the exclusive fief of private and public news organizations. Consequently, audiences in the digital era are turning into publics of users who engage with online news media as technological tools they rely on to obtain information, but also as content providers that call for individual and social interpretation and evaluation (Livingstone, 2003, 2005).

This twofold engagement of the public with online news media raises the question of why and how they come to trust those media. Yet, except for a few authors who have explicitly focused on trust in the media (Bakir \& Barlow, 2007; Coleman et al., 2009; Kohring \& Matthes, 2007; Ziomek, 2005), most contemporary media scholars tend to prefer credibility over trust and, in so doing, they analyze and measure the former to draw conclusions about the latter (Jo, 2005; Johnson \& Kaye, 2004; 2009; Kiousis, 2001; Lee, 2010; Metzger \& Flanagin, 2008; Metzger et al., 2010; Jackob, 2010; Tsfati, 2010; 
Tsfati \& Capella, 2003). As a result, trust in online news media still remains an elusive concept because it is often conflated with, or reduced to, media credibility.

However, trust scholars have provided theoretical insights that are useful both to disentangle trust from its intuitive relatives (e.g., reliance and confidence) and to avoid conflating credibility with trust. Those insights will constitute the theoretical basis on which this research is articulated. For instance, Pettit (2004, p. 109) has argued that reliance makes reference to how people engage with others "[...] in a way that is premised on their being of a certain character or on their being likely to act under various circumstances in a certain way". Thus, relying on someone in this sense is not so markedly different from relying on a non-personal entity like an object or tool. Reliance implies a basic level of engagement with objects, people, and institutions, and can be reinforced by people's automatic appraisals of social rules, roles, and routines. In other words, reliance runs in the background of people's everyday interactions and is not thematized until the object, person, or institution being relied upon behaves in unexpected ways.

On the other hand, confidence takes place when people expect that another individual, group, or institution will act reliably. It refers to an individual's positive, unchallenged expectation that someone else's future behavior will be constant and beneficial to him or her. Confidence implies an optimistic feeling that (familiar) things and behaviors will remain constant. However, as Luhmann (1988) has pointed out, the basic difference between confidence and trust is that the latter involves choosing among available alternatives and acting accordingly despite the fact that those alternatives may initially imply dealing with risk and uncertainty. It should be noted, though, that in some cases a feedback loop can take place between confidence and trust, for instance, when long-term honored trust becomes established as a default condition between two agents. In such cases trust can be soundly conceived as confidence provided that the trustee continues to honor the trust being placed on him or her.

Finally, some authors have taken trust to be a three-part relation: A (trustor) trusts B (trustee) to do, or with respect to X (Baier, 1986; Hardin, 2002). This view implies that trust is always conditional, situated, and qualified, which means that it is directed at something specific (action, event, behavior) for which the trustee is deemed trustworthy. In this view, trust is mostly formed and maintained not because of a fixed set of antecedent variables (which may include perceptions and judgments 
of trustworthiness) but because of the dynamic conditions that structure context-specific commitments, conditions that determine the nature of the trustor's dependency on, and expectations about the trustee. In this sense, trust implies a performative, enacting dimension in which one assumes an engagement with an agent and chooses a course of action accordingly despite the uncertainty implied in such a choice.

It appears then that trust can be soundly framed as a mode of agency entailing a personal engagement - incorporating cognitive, affective, and behavioral dimensions - with some agent (individual or group) and with respect to something. This makes a significant difference for examining the differences between trust, reliance and confidence, and how they vary along the certainty/uncertainty dimension. In addition, although trust implies at some point assessments of credibility (i.e., expertise and trustworthiness), it does not boil down to a simple belief, judgment, or awareness of someone's credibility. One can judge an agent credible without necessarily trusting her because judgments, beliefs, and awareness do not automatically translate into practical and situated engagement and action.

As far as online news media are concerned, one can easily identify the trustor (users/audiences) and the trustee (media/journalist/blogger). However, it is difficult to provide an a priori definition of $\mathrm{X}$ since it may stand for whatever media-related factor users deem worth trusting. Identifying which of these factors French-speaking Belgian newsreaders consider worth trusting is the subject of the following sections.

\section{Method}

This research has been conceived as a qualitative, constructivist investigation into public trust in online news in French-speaking Belgium. It aims at understanding the public's reception of online news media, and the levels of trust they assign to those media.

The basic cluster of media selected for this study includes three online newspapers (La Libre, Le Soir, La Dernière Heure), two online mainstream radio and television organizations (RTBF Info, RTL Info), the French version of one site of citizen journalism (Medium4You.be), two French websites of participatory journalism (Rue89, AgoraVox), and some French-speaking blogs (e.g., crise dans les medias, écologie de l'information).

A purposive sampling was conducted for this research. Since the fieldwork was principally to be concerned with understanding the 
public's engagement with and motivation to trust online news media, we opted to focus on individuals who are active users of those media in order to capitalize on their first-hand knowledge and experience with online news, their news-related social practices, and their potential levels of media engagement.

Respondents were recruited via the selected media's fan groups on Facebook and followers on Twitter, and through a randomized list of followers of available French-speaking blogs. The main data collection modality consisted of semi structured interviews (offline and online, depending on geographical constraints). For respondents who did not want or were not able to grant a face-to-face interview, two other modalities were arranged: e-mail questionnaire and e-mail interview. No hierarchy was implied among the different kinds of texts (i.e., questionnaire, interview); the three types were treated equally in terms of their contribution to the data analysis.

The final sample is composed of 37 respondents (26 male, 11 female, ages 25-60, M=34), having mostly high school or university education) corresponding to 7 e-mail interviews, 10 e-mail questionnaires and 20 semi-structured interviews ( 8 offline, 12 online). All respondents provided informed consent and were granted complete confidentiality and anonymity. Face-to-face interviews were audio recorded and online interviews were audio/video recorded. Completed questionnaires, e-mails and transcriptions of interviews were loaded into NVivo software, coded following Charmaz's (2006) twofold process of initial and focused coding, and subject to content analysis.

\section{Trust in Online News Media: The Point of View of the Audience}

In order to disclose their conceptions of online media credibility and trust, and the extent to which those conceptions are intertwined with their levels of engagement with online news media, respondents were asked to describe their activities when going online for news, to define in their own words both a credible media and a trustworthy one, and to explain how they came to trust online news media.

Answers to the question about online activities revealed different attitudes towards online media and levels of participation and engagement. Some respondents $(27 \%)$ declared to be just regular readers who neither post comments on articles nor participate in online forums, others (43\%) said they were active users who regularly post comments and engage in online discussion with journalists and other 
newsreaders, and still others defined themselves as content creators or "curators" who have already published articles on participatory media $(19 \%)$ and/or write a blog (11\%) (Figure 1).

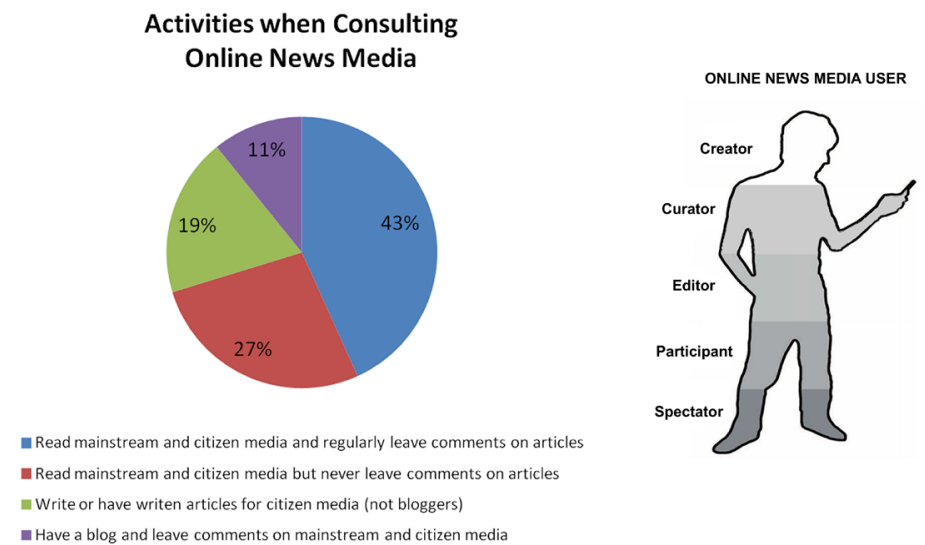

Figure 1. Online activities described by respondents $(n=37)$

Besides their different levels of direct participation in online news websites, respondents declared they regularly send tweets about national or international news and/or share links to news on their Facebook profiles.

Respondents who never post comments on online news websites invoked several reasons for doing so, including "the lack of continuity between the article's topic and people's comments on it", "the presence of 'trolls' and other annoying people who monopolize and undermine the discussion", "the quality and relevance of the article to their needs", and "the insufficient moderation in online forums". Prolific respondents — including bloggers — described their active searching for and participating in online media as a result of their "obsessive" need to keep constantly informed.

These different attitudinal and behavioral patterns related to online news suggest that respondents' levels of engagement with online media are driven by individual preferences, the extent to which online news media contents correspond to their needs for information, their 
perceptions of other newsreaders in a media-related online space, and appraisals of their own roles as newsreaders.

Answers to the online media credibility question were in line with most predictors (Johnson \& Kaye, 2004, 2009; Kiousis, 2001) and heuristics (Metzger et al., 2010) reported in the extant literature. Respondents defined credible online news media in terms of believability, expertise, accuracy, having a well-established reputation, reliability, balance, and trustworthiness (Figure 2). Eight out of thirtyseven $(21 \%)$ respondents explicitly alluded to trustworthiness as a feature of a credible online news media. However, for most respondents in the sample there is a difference between judging an online news site credible and considering it trustworthy. On closer semantic inspection of their answers (Figure 3), online media credibility was mostly conceived in terms of the media's technical competence to provide accurate information rather than their capacity to inspire trust.

\section{Credibility Factors invoked for Online News Media ( $N=37$ )}

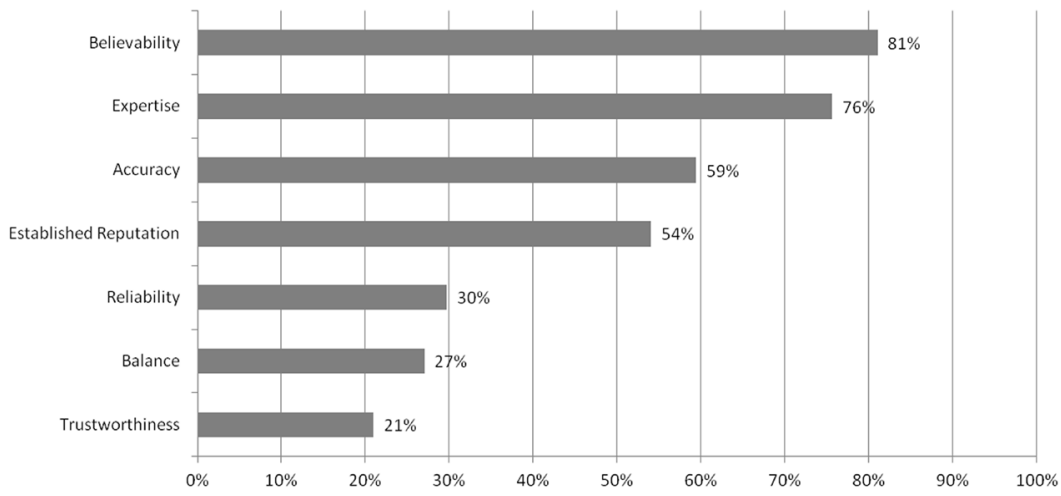

Figure 2. Credibility factors for online news media 


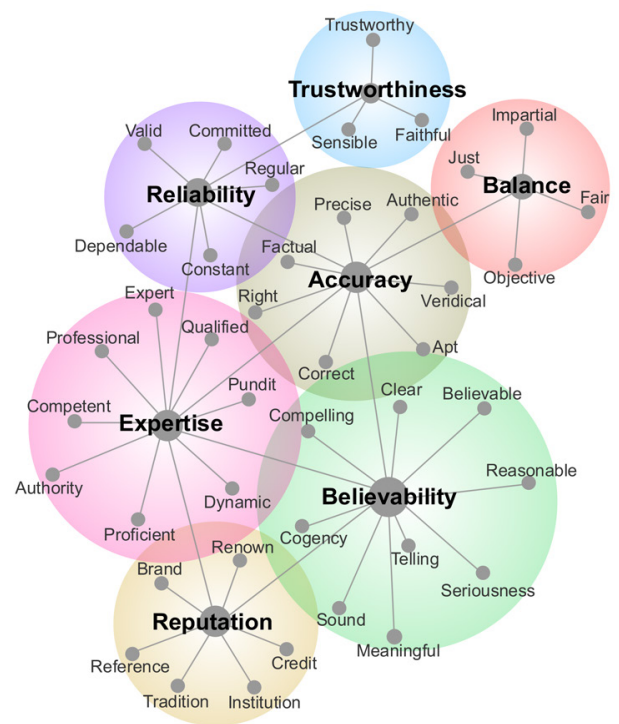

Figure 3. Semantic mapping of credibility factors for online news media

On the other hand, answers to the trustworthy media question mostly revealed value-laden evaluations of media practices and roles. Respondents described trustworthy online news media in terms of truthfulness, transparency, accountability, politically unbiased, showing concern for the public interest, fulfilling public expectations, stability, valuable, and credible (Figure 4), and a semantic mapping of the answers revealed the strong normative leitmotiv permeating their conceptions of online media trustworthiness (Figure 5). 


\section{Trust-related Factors invoked for Online News Media ( $\mathrm{N}=37$ )}

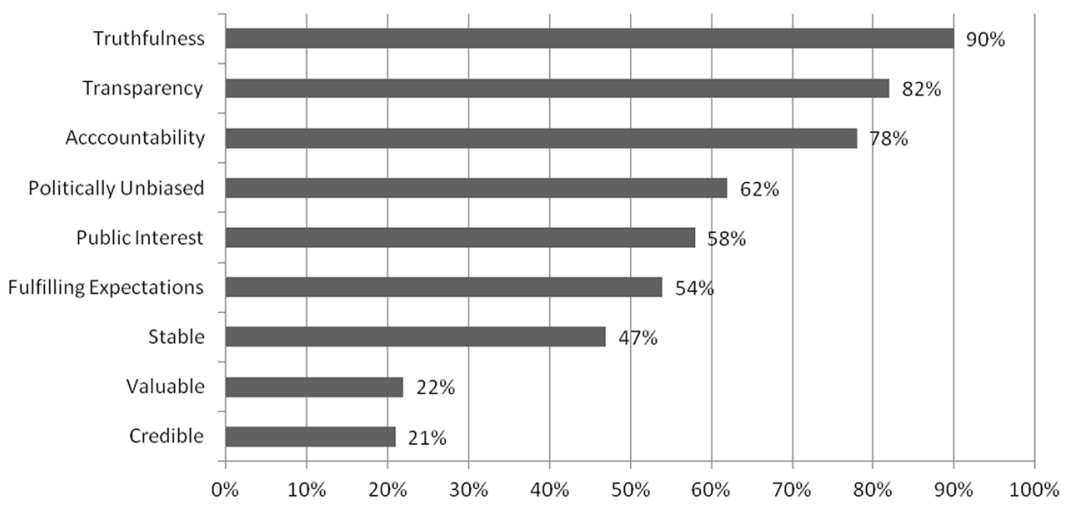

Figure 4. Trust-related factors for online news media

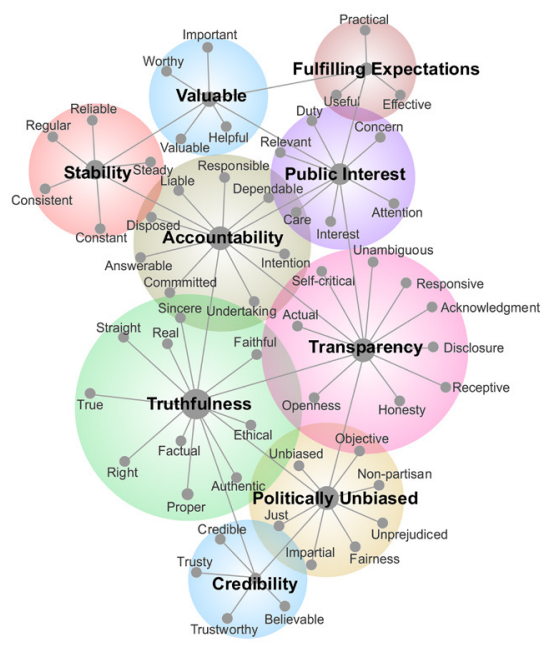

Figure 5. Semantic mapping of Trust-related factors for online news media

It should be noted, though, that respondents who previously alluded to trustworthiness as a factor of credibility consistently posited this time credibility as a factor implied in assessments of media trustworthiness. This outcome can be explained as a result of their tendency to put media's technical competence and trustworthiness at the same evaluative level. However, for the majority of respondents, 
credibility and trustworthiness appear to belong to two different levels of media evaluation, which suggests that perceptions of (and dispositions to) trust or distrust online media are largely motivated by normative (e.g., ethical) appraisals of media's trustworthiness. Nevertheless, this does not exclude that for some people credibility assessments, as a way of sorting out reliable and unreliable media, do play a role in their identifying trustworthy news providers.

As for the question about how they came to trust online news media, answers varied along two axes. The first axis was familiarity with the codes and conventions of mainstream media, and respondents explained it in terms of their being former and loyal consumers of print/ broadcast versions of online mainstream media. Answers along this axis revealed blending patterns of reliance (e.g. "I've always done so") and confidence (e.g., "I only trust what I know"), which are characterized not only by people's previous knowledge and experience of traditional media, but also by their accepting a level of media-related assurance that rules out any need to look for alternatives elsewhere. Although such patterns characterize most of what those newsreaders call trust, it should be noted that their engagement with traditional media is mostly marked by a level of certainty associated to following a routine-like way of getting the news from the same news providers and thus being free from having to check up the quality and trustworthiness of alternative media.

The second axis was a process of familiarization with alternative news media and respondents expressed it in terms of their willingness to search for new, non-mainstream news media despite the fact that they were not initially sure of those media's quality. Some respondents described their "risk-oriented" experiences with alternative media as serendipitous encounters with citizen journalism or blogs, others recalled them as the result of recommendations given by friends or members of their social networks, and still others talked about looking for alternatives because of their dissatisfaction with online mainstream media. Some examples of their motivations to assume these risk-taking attitudes are "looking for critical angles one can't find in traditional online media", "following people whose insights and reflections are not tainted by traditional media ideology", and "giving a chance to fresh, promising voices on the blogosphere". Familiarization in this sense is to be understood as a twofold process implying the suspension of uncertain beliefs about the quality/relevance of a given media and the 
subsequent engagement with that media on the basis of its perceived trustworthiness.

Taken together, the answers examined in this section revealed that different degrees of media dependency, awareness of uncertainty, individual routines of information seeking, attitudes towards online media, and individual preferences account for the multilayered experience we may call trust in online news media. Finally, for some respondents perceptions of credibility affect their conceptions and dispositions to trust a given media. However, for most respondents in the sample credibility appears to fall within the technical domain of accurate reporting and is not always a sufficient condition for them to actually trust online news media.

\section{Heuristics for Building up Trust in Online News}

Respondents were also asked about the criteria they adopt to decide whether or not they can trust online news. A content analysis of their answers revealed several heuristics implemented to that effect: transparency, accountability, reputation, and recommendation. The relevance of these heuristics for trust stems from the fact that they function as fast and frugal rules enabling newsreaders to search for and draw upon - regularities in the online news environment in order to attribute trustworthiness to, and to engage in trusting relationships with, online journalists and news media.

\section{The Transparency Heuristic}

Transparency came to the fore via respondents' criticism on (1) the selection of topics for publication in mainstream media and (2) the (dis) advantages of disclosure of editorial policies in alternative media. The selection of topics for publication — also known as agenda setting was a recurrent issue in most respondents' evaluations of mainstream media trustworthiness. The common ground of those evaluations was a widespread skepticism about the reasons and interests lying behind the selection process and the alleged independency of the media from external (political or economic) forces. Respondents pointed out that an attentive look at how the news is framed as well as the frequency of delivery can raise doubts about the transparency of the media. Among the reasons motivating such skepticism about mainstream online media transparency are, for instance, "the excessive coverage of 
certain political figures", "the over-hype of shocking stories", and "the widespread moral panic over financial affairs".

On the other hand, respondents' appraisals of the (dis)advantages of editorial policy disclosure were principally concerned with alternative journalism platforms that do not have the vertical gatekeeping policies typical of private and public media organizations. Two trends in evaluating such policy disclosure were manifest. First, several respondents highlighted the positive effects of editorial disclosure upon their engagement with, and dispositions to trust, alternative media. This was the case for the open editorial policies of participatory media like AgoraVox, and one respondent described it as follows: "everyone willing to comply with them [open editorial policies] can share her own views and engage in real discussion with other people".

Second, not all about the disclosure of editorial policies in alternative media seems to bring positive outcomes. Indeed, the growing corporate ownership of some alternative media - along with the aim to keep a high journalistic standard — seems to push editorial decision making in a somewhat discriminatory direction. In this sense, other respondents pointed out that editorial policies of alternative media that have gradually become hermetic to citizens' contributions bring about mistrust in those media, which, in turn, leads to marked patterns of inattention and potential nonconsumption. Those issues were mostly raised in relation to alternative platforms like Rue89 in which, according to another respondent, "only journalists and their expert friends - for the most part journalism students - are leading most of the topics being investigated in Rue89, and the 'public' is no longer the 'third voice' being heard on their website".

All in all, respondents' perceptions and evaluations of transparency revealed concerns about the process through which newsgathering policies are brought to public view. Accordingly, perceptions and evaluations of transparency appeared to play a significant role in people's assessments of media trustworthiness, their levels of engagement with online media, and their willingness to trust (or distrust) those media.

\section{The Accountability Heuristic}

The accountability heuristic principally concerned public evaluation of professional and citizen journalists' honesty and commitment to publicly recognize their errors when publishing inaccurate or incomplete information. In most respondents' answers, 
mistake acknowledgment entailed an ethical dimension related to the consequences of media failures to fully verify the information they publish online. Although verification is a journalistic principle observed by most media outlets concerned with public knowledge, sometimes inaccurate or incomplete information can pass through the tight filters of online newsrooms. Several respondents pointed out this issue and, at the same time, emphasized concerns about the need for online journalists to honor deontological commitments expected to inform the whole process of information verification. This point is significant because, in general, the more prominent or shocking some information appears to be, the faster it spreads. Yet in cases in which it turns out to be false, the mechanisms for retracting or correcting misrepresentations can never proceed as quickly and broadly as the original dispersion, and the ethical consequences can be lasting (e.g., "harming people by publishing insufficiently verified information").

The issue at stake here is that by delivering inaccurate or incomplete information, the media put their own trustworthiness in jeopardy, and this situation has negative retroactive consequences: Not only the final product (the information actually published) is misleading, but, by implication, the process through which it was validated by journalists (source verification) turned out to be flawed.

Although media failure to fully verify information was taken by respondents as a criterion that affects their decisions to trust those media, the impact of such failure appeared to be largely contingent on the type of information delivered. While providing inexact information about celebrities, sports, or fashion was regarded by most respondents as relatively inconsequential, failure to provide accurate information about political, social, or economic issues was considered highly critical. This difference stems from respondents' appraisals of some topics of the agenda setting as "futile or without important consequences for most people's lives" and others as "serious and relevant to public knowledge and civic life".

Notwithstanding the importance of adhering to professional deontology to avoid delivering inaccurate information, most respondents recognized that journalists are more often than not driven by the "immediacy imperative" and intense media competition so that they may be forced to make risky choices, and thus, fail to provide complete information when publishing their articles online.

Respondents' conceptions of media accountability are worth noting here as they imply a shift from evaluations of media trustworthiness as a 
cold epistemic indicator of the media's capacity to provide accurate and objective information to trustworthiness as an integrity-related quality having socially relevant, ethical import. In most of their answers, respondents considered public acknowledgment of mistakes as a trustful sign of commitments to sincerity and integrity by journalists and the media. Consequently, public acknowledgment of mistakes appeared to play a significant role in fostering trust in online news media, provided these media are willing enough to disclose and honor their mistakefixing policies.

\section{The Reputation Heuristic}

Respondents alluded to reputation as (1) the effects of the reputational transfer from print and broadcast media to their online versions and as (2) the individual reputation or personal branding established by individual journalists and bloggers. For some respondents, transferred reputation formed the basis of their confidence in mainstream online news media. Even though they expressed it in terms of trust, their answers mostly revealed that they continue holding positive and somewhat utilitarian expectations about mainstream online news media despite some disappointing episodes.

Yet for other respondents who have previously evaluated mainstream media reputation in negative terms, the transfer to the online format carries with it a strong side effect: instead of reinforcing trust, it appears to thwart trust by triggering negative judgments about the originality of new stories and a tendency to homogenize or cannibalize reporting by just recycling news produced by other sources.

Two opposing views of transferred reputation can thus be highlighted here: a positive one, which underpins and fosters confident expectations about online media's practices and roles, and a negative one, based on perceptions of the extent to which mainstream media flaws extend to their online versions. Accordingly, transferred reputation seems to play different roles in building trust or distrust in online news, depending on respondents' personal experience with and beliefs about offline media.

The second way in which reputation was evoked has to do with individual reputation or personal branding. Although much of the current discussion of personal branding has focused on the noxious consequences of self-promotion and viral marketing for journalism (Weingarten, 2011), several respondents referred to personal branding 
positively in terms of online journalists' (and bloggers') individual reputation sustained by quality reporting, relevant news assessment, and open conversation with followers in social networks. However, respondents do not consider every online journalist or blogger who uses social networks as equally trustworthy. Indeed, some online journalists are perceived as being merely concerned with self-advertising or "bragging, showing themselves off instead of building real bridges with their public".

So there seems to be more for personal branding to beget trust than simply appearing on the online radar and being widely visible. Nevertheless, as far as mainstream online news media are concerned, personal branding has two trust-related features worth underlining here. First, insofar as it concerns the public's perception and assessment of a journalist's reputation beyond the media he or she works for, personal branding suggests a shift in trust from an institutional level-based on conceptions of the media as a remote system the principle and mechanisms of which are opaque for the average user - to a level that resembles interpersonal or relational trust. This shift allows online newsreaders to single out a specific journalist from an impersonal and heterogeneous system, and engage in assessing his or her quality reporting based on the proximity afforded by social networks.

The representation of a journalist's identity (his or her personal brand) appears to be carefully crafted to convey trustworthiness through a rich collection of reputation cues. Respondents' reports on personal branding suggest that they understand and embrace those new representations of identity and adapt their "news seeking practice" accordingly. Thus personal branding understood as an identity (re) presentation plays a key role in the process of evaluating online journalists' trustworthiness as far as it provides newsreaders with reputational cues they can take as heuristics to assess whether or not a journalist's competence and openness to dialogue is worth trusting.

\section{The Recommendation Heuristic}

Among the most important conditions of trust are family relationships, friendships, and networked contexts, which provide not only grounds for people to be trustworthy, but also opportunities to place one's trust in those who deserve it. In this sense, in most everyday situations in which people want to find someone who is trustworthy 
or need to check on someone's trustworthiness, they tend to rely on network-based trust and perceptions of trustworthiness.

In consonance with this idea, respondents declared that in order to consider whether or not they can trust online news media, they draw on their own direct experience in following journalists and bloggers, but also on media recommendations provided by trustworthy members of their social networks. Again, this shift from evaluating online media as an abstract system to singling out some of their representatives suggests a fragmentation of online media into discrete units whose trustworthiness is easier to appraise. The basic principle here seems to be the belief that others' recommendations and testimonials within one's network have an added value for the network itself. That is, members of the network act as peer-gatekeepers who filter out news worth sharing according to an implicit idea of the network's interests.

Respondents pointed out that although the recognition of shared interests, recommendations, and testimonials within their social networks does not automatically bring about trust (this seems to happen only in cases where specific journalists and media have already been recognized as trustworthy sources), it nevertheless frames their dispositions to trust online journalists and the media. As one respondent stated:

"For me, messages and tweets concerning media or journalists I'm not acquainted with are recommendations made by someone with whom I share the same interests and this certainly makes me adopt a somewhat favorable attitude towards the source, but I still have to give it a second look before deciding whether or not it's worth trusting".

It appears then that social networking systems like Facebook and Twitter afford a virtual agora in which respondents get access to recommendation and testimonial resources they draw on to make up their minds about online news media and journalists' trustworthiness. Furthermore, the recommendation heuristic also emphasizes the idea that the active routines and roles played by network members are crucial not only for building trust among members but also for shaping the conditions under which any flow of information that enters the network may be judged reliable and trustworthy. Consequently, patterns of online media reception and evaluation of trustworthiness within social networks have to be understood against the background of newsreaders' individual levels of engagement with those networks and the dynamics of testimonial and recommendation within those networks. 


\section{Conclusions}

Current research on trust in online news media has mostly focused on assessments of media credibility, somewhat conflating credibility with trust and, by the same token, missing some of the latter's epistemological and phenomenological essentials. To be sure, media credibility is an important element to understand how people perceive and evaluate online news media as well as how they come to build their true-beliefs capital as informed citizens. Yet media credibility only accounts for half the story of public trust in the media. Judgments of credibility certainly constitute significant factors people take into account when dealing with complex and multifarious sources of information, but such perceptions and judgments alone cannot fully account for the agency/engagement dimension underpinning the public's trusting behaviors and attitudes towards online news media.

According to the results presented in this research, trust in online news media means not so much a binary and rather trivial choice between trusting and distrusting, but between either accepting a certain level of assurance - reliance and confidence based on individual information seeking routines and roles attributed to online news media - or looking for further alternatives and safeguards. Trust amounts to reliance and confidence for respondents who do not question online mainstream media and feel no need to look for news elsewhere. Reliance and confidence in those cases gather their strength from respondents' familiarity with offline versions of those media. For other respondents, trust turns into confidence as far as the initial trust they placed in online journalists and bloggers via familiarization with those media continues to be honored. Finally, for still others trust takes place when they place a bet on alternative platforms such as citizen media and blogs, and decide to engage with those media despite their being aware of the uncertainty implied in placing such a bet. Trust appears in this case as a risk-oriented attitude revealing respondents' suspension of initial doubts about the quality and relevance of new sources of information and analysis.

Furthermore, respondents also reported individual and social heuristics for building up trust, which testify for the active and reflective dimensions inherent to trust in online media. Such heuristics help us understand the conditions under which newsreaders not only go beyond a given level of information and knowledge about online media but also negotiate different degrees of assurance when dealing with those media. 
Although this research is subject to the constraints inherent to qualitative approaches, namely limited validity and generalizability, it has nevertheless shed light upon the ways in which the public comes not only to perceive, but to engage in trusting relationships with online news media. Respondents in this study have a background as regular users of social networking sites, which to a large extent accounts for both their particular views of the news, journalists, and bloggers, and how they come to evaluate, engage with, and trust online media. Insofar as the social affordances provided by social networking sites foster particular models of information evaluation, the trust-related expectations held by users of these sites may be somewhat qualitatively different from those of active consumers of online news media who do not regularly use social networking sites as a means to obtain, share, and evaluate online news. However, such qualitative differences allow us to highlight the complexity of a growing trend in online news reception, namely increasingly networked news consumption and evaluation. Academic and professional consideration of this trend will open up new windows to future research on public trust in online news media and, at the same time, will provide insights into eventual shifts towards neo-journalistic practices.

\section{References}

Baier, A. (1986). Trust and Antitrust. Ethics, 96(2), 231-260.

Bakir, V., \& Barlow, D. (Eds.) (2007). Communicating in the Age of Suspicion: Trust and the Media. New York: Palgrave Macmillan.

Charmaz, K. (2006). Constructing Grounded Theory. London: Sage.

Coleman, S., Anthony, S., \& Morrison, D. (2009). Public Trust in the News: A Constructivist Study of the Social Life of the News. Oxford: Reuters Institute for the Study of Journalism.

Hardin, R. (2002). Trust and Trustworthiness. New York: Russell Sage Foundation.

Jackob, N. (2010). No alternatives? The Relationship between Perceived Media Dependency, Use of Alternative Information Sources, and General Trust in Mass Media, International Journal of Communication, 4, 589-606.

Jo, S. (2005). The Effect of Online Media Credibility on Trust Relationships, Journal of Website Promotion, 1(2), 57-78.

Johnson, T., \& Kaye, B. (2004). Wag the Blog: How Reliance on Traditional Media and the Internet Influence Credibility Perceptions of Weblogs among Blog Users, Journalism and Mass Communication Quarterly, 81(3), 622-642. 
Johnson, T., \& Kaye, B. (2009). In Blog We Trust? Deciphering Credibility of Components of the Internet Among Politically Interested Internet Users, Computers in Human Behavior, 25, 175-182.

Kiousis, S. (2001). Public Trust or Mistrust? Perceptions of Media Credibility in the Information Age, Mass Communication and Society, 4(4), 381-403.

Kohring, M., \& Matthes, J. (2007). Trust in News Media: Development and Validation of a Multidimensional Scale, Communication Research, 34(2), 231-252.

Lee, T. (2010). Why They Don't Trust the Media? An Examination of Factors Predicting Trust, American Behavioral Scientist, 54(1), 8-21.

Livingstone, S. (2003). The Changing Nature of Audiences: From the Mass Audience to the Interactive Media User. In A. N. Valdivia (Ed), A Companion to Media Studies (pp. 337-359). London: Blackwell.

Livingstone, S. (2005). On the Relation between Audiences and Publics. In S. Livingstone (Ed), Audiences and Publics: When Cultural Engagement Matters for the Public Sphere (pp. 17-41). Bristol, UK: Intellect.

Luhmann, N. (1988). Familiarity, Confidence, Trust: Problems and Alternatives. In D. Gambetta (Ed.) Trust: Making and Breaking Co-operative Relations (pp. 94-107). Oxford: Basil Blackwell.

Meikle, G., \& Redden, G.(Eds) (2011). News Online: Transformations and Continuities. London: Palgrave Macmillan.

Metzger, M., \& Flanagin, A. (2008). Digital Media, Youth, and Credibility. Cambridge, MA, MIT Press.

Metzger, M., Flanagin, A. \& Medders, R. (2010). "Social and Heuristic Approaches to Credibility Evaluation Online", Journal of Communication, 60, 413-439.

Pettit, P. (2004). Trust, Reliance and the Internet, Analyse \& Kritik, 26, 108-121.

Silverstone, R. \& Hirsh, E. (Eds) (2005). Consuming Technologies: Media and Information in Domestic Spaces. London: Routledge.

Tsfati, Y. (2010). Online News Exposure and Trust in the Mainstream Media: Exploring Possible Associations. American Behavioral Scientist, 54(1), 22-42.

Tsfati, Y. \& Capella, J. (2003). Do People Watch What they Do Not Trust? Exploring the Association between News Media Skepticism and Exposure, Communication Research, 30(5), 504-529.

Weingarten, G. (2011). How 'Branding' is Ruining Journalism, The Washington Post, 23 June 2011. Disponible à: http://www.washingtonpost.com/lifestyle/magazine/ gene-weingarten-how-branding-is-ruining-journalism/2011/06/07/AGBegthH story.html Accessed 22 July 2011.

Ziomek, J. (2005). Journalism, Transparency and the Public Trust. A Report of the Eight Annual Aspen Institute Conference on Journalism and Society. Washington, DC: The Aspen Institute. 